\title{
Antisense-mediated Reduction in Insulin-like Growth Factor-I Receptor Expression Suppresses the Malignant Phenotype of a Human Alveolar Rhabdomyosarcoma
}

\author{
David N. Shapiro, ${ }^{\star \neq 1}$ Bart G. Jones, ${ }^{*}$ Linda H. Shapiro, * Peter Dias, ${ }^{\mathbf{5}}$ and Peter J. Houghton ${ }^{\star \|}$ \\ Departments of * Experimental Oncology, ${ }^{\ddagger}$ Hematology/Oncology, and ${ }^{8}$ Molecular Pharmacology, St. Jude Children's \\ Research Hospital, Memphis, Tennessee 38105; and Departments of ${ }^{\top}$ Pediatrics and "Pharmacology, \\ University of Tennessee College of Medicine, Memphis, Tennessee 38163
}

\begin{abstract}
The expression of the insulin-like growth factors (IGFs) and their receptors has been linked to cellular proliferation and tumorigenicity in a number of model systems. Since rhabdomyosarcoma cells express IGF-I receptors, an autocrine or paracrine loop involving this receptor and its ligands could be responsible in part for the growth characteristics of this tumor. To assess directly the role of the IGF-I receptor in rhabdomyosarcoma cell growth and tumorigenicity, a human alveolar rhabdomyosarcoma cell line with high IGF-I receptor expression was transfected with an amplifiable IGF-I receptor antisense expression vector. Four unique, transfected clones were analyzed and found to have reduced IGF-I receptor expression relative to the parental line. Integration of the antisense sequence was demonstrated by Southern blot analysis, and expression of antisense message in these clones was shown by $\mathrm{S1}$ nuclease protection assay. Reduced IGF-I receptor surface expression in the transfectants was shown by decreased immunofluorescence with an IGF-I receptor monoclonal antibody and by decreased IGFI binding as measured by Scatchard analysis. These clones had markedly reduced growth rates in vitro, impaired colony formation in soft agar, and failed to form tumors in immunodeficient mice when compared with vectortransfected clones. These results demonstrate that reduction of IGF-I receptor expression can inhibit both the in vitro and in vivo growth of a human rhabdomyosarcoma cell line and suggest a role for the IGF-I receptor in mediating neoplastic growth in this mesenchymally derived tumor. $(J$. Clin. Invest. 1994. 94:1235-1242.) Key words: insulin-like growth factor receptor • antisense RNA • downregulation • paracrine $\bullet$ autocrine
\end{abstract}

\section{Introduction}

The insulin-like growth factors I and II (IGFs), also known as somatomedins, are two single-chain polypeptide hormones that are structurally related to proinsulin and are primarily involved

Address correspondence to David N. Shapiro, M.D., Department of Experimental Oncology, St. Jude Children's Research Hospital, 332 North Lauderdale, Memphis, TN 38105.

Received for publication 15 July 1993 and in revised form 4 May 1994.

J. Clin. Invest.

(C) The American Society for Clinical Investigation, Inc 0021-9738/94/09/1235/08 \$2.00

Volume 94, September 1994, 1235-1242 in promoting vertebrate growth and development (1). The biologic actions of IGFs are mediated by three different cell-surface receptors that bind these peptides with different affinities: the IGF-I receptor (IGF-IR), ${ }^{1}$ the IGF-II receptor (IGF-IIR), and the insulin receptor (2). The insulin and the IGF-I receptors are structurally similar heterotetramers with ligand-activated tyrosine kinase activity in their cytoplasmic portions, which is necessary for signal transduction. These receptors bind their cognate ligands with high affinity and both heterologous peptides with lower affinity; the IGF-I receptor also binds IGF-II with similar high affinity (3). By contrast, IGF-IIR is structurally identical to the mannose-6-phosphate receptor, is without intrinsic tyrosine kinase activity, and has not been linked to the growth-promoting actions of the IGFs $(4,5)$. Of interest, however, IGF-IIR was shown recently to mediate IGF-II-induced motility in human rhabdomyoblasts $(6,7)$.

Both IGF-I and -II have been shown to stimulate myoblast proliferation and differentiation, as well as to promote nutrient uptake and inhibit proteolysis; these diverse biological activities appear to be exclusively mediated through IGF-IR (3, 8-11). Similar results have also been reported for several human rhabdomyosarcoma cell lines, where IGF-II-induced signaling through IGF-IR has been implicated in the autocrine growth of these tumors (6). By contrast, a potential role for IGF-I or IGFII and the IGF-IR in promoting tumor growth in vivo is unclear. Although some mesenchymally derived tumors have been found to secrete these growth factors, their precise role in tumorigenesis remains speculative, since the addition of IGF-I or IGF-II to cultured cells does not result in transformation (12-14). Indirect evidence suggesting the capacity for IGF-IR to promote neoplastic growth has been reported by Kaleko et al. (15). In these studies, overexpression of IGF-IR in NIH 3T3 cells resulted in ligand-dependent neoplastic transformation as well as the ability to form tumors in nude mice, suggesting that, when amplified, this ubiquitous growth factor receptor functions as an oncogenic protein.

This study was designed to investigate the possibility that the malignant phenotype of rhabdomyosarcoma cells could be altered by stably lowering IGF-IR levels using antisense RNA. The antisense RNA technique leads to a reduction in the expression of a target gene at the protein level through the formation of a specific double-stranded RNA hybrid which interferes with normal mRNA transport and translation (16, 17). We have constitutively expressed IGF-IR antisense transcripts in a human alveolar rhabdomyosarcoma cell line which normally has a high

1. Abbreviations used in this paper: dhfr, dihydrofolate reductase; IGFIR and IGF-IIR, IGF receptors I and II; MTX, methotrexate; RFI, relative fluorescence index. 
density of IGF-IR at the cell surface and forms aggressive tumors in immunodeficient mice. The antisense clones were analyzed for integration and expression of transfected sequences, IGF-IR receptor number, and in vitro and in vivo growth characteristics. Clones with reduced IGF-IR expression grew at a slower rate in vitro and were less tumorigenic in immunodeficient mice, when compared with parental or vector control lines.

\section{Methods}

Cell culture. The human alveolar rhabdomyosarcoma cell line Rh30 was established from the bone marrow of a patient with metastatic tumor and has been described previously (18). The cells were grown in DME supplemented with $2 \mathrm{mM}$ glutamine, $10 \% \mathrm{FCS}$, and $50 \mu \mathrm{g} / \mathrm{ml}$ gentamicin. Cells were maintained at $37^{\circ} \mathrm{C}$ with $5 \% \mathrm{CO}_{2}$ and subcultured by trypsinization.

Soft agar assays. Cell suspensions were plated $\left(2.5 \times 10^{3}\right.$ cells per 35-mm dish) in semisolid medium containing 0.3\% Bacto-Agar (Difco Laboratories, Detroit, MI), DME, 10\% heat-inactivated, dialyzed FCS, and $50 \mu \mathrm{g} / \mathrm{ml}$ gentamicin. When used to inhibit colony formation, the IGF-IR monoclonal antibody $\alpha$ IR-3 (Oncogene Science Inc., Manhasset, NY) was included at a final concentration of $0.5 \mu \mathrm{g} / \mathrm{ml}$ (19). Heat-inactivated serum was used as a precaution to prevent potential complement-mediated cell lysis in the presence of the antibody. The dishes were incubated at $37^{\circ} \mathrm{C}$ in a humidified atmosphere containing $7 \% \mathrm{CO}_{2}$, and colonies were scored after $21 \mathrm{~d}$.

Vector constructs and transfections. The IGF-IR antisense expression plasmid [ $\mathrm{pSV}_{2}$ IGF-IRAS(dhfr)] was constructed by isolating an EcoRI fragment containing the first $700 \mathrm{bp}$ of coding sequence from the IGF-IR cDNA-containing plasmid pIGF-IR.8. This region partially encodes the $\alpha$ subunit of the heterotetrameric receptor (20). This fragment was ligated into the unique SmaI site of the mammalian expression $\mathrm{pSV}_{2}(\mathrm{dhfr})$ after repair with the Klenow fragment of DNA polymerase I (21) (see Fig. 2). The antisense orientation of this new construction was confirmed by restriction endonuclease digestion. The expression plasmid $\mathrm{pSV}_{2}$ (dhfr) contains a complete transcription unit for a mutant dihydrofolate reductase ( $\mathrm{dhfr}$ ) with an increased $K_{\mathrm{m}}$ for methotrexate (MTX), enabling selective amplification of plasmid sequences in mammalian cells in the presence of high concentrations of MTX.

Stable Rh30 transfectants were obtained by cotransfection of the antisense expression plasmid or vector-only DNA with $\mathrm{pSV}_{2}$ neo DNA (22) according to the method of Chen and Okayama (23). Briefly, Rh30 cells growing exponentially in DME supplemented with $10 \%$ dialyzed FCS were seeded at $5 \times 10^{5}$ cells per $10-\mathrm{cm}$ dish. These cells were then cotransfected with a total of $30 \mu \mathrm{g}$ of DNA at a 10:1 molar ratio of antisense or vector DNAs to $\mathrm{pSV}_{2}$ neo DNA in BES $(N, N$-bis[2-hydroxyethyl]-2-aminoethanesulfonic acid)-buffered calcium phosphate. Cells were incubated at $35^{\circ} \mathrm{C}$ in $3 \% \mathrm{CO}_{2}$ for $48 \mathrm{~h}$ before being split $1: 10$ and selected in medium containing G418 at $400 \mu \mathrm{g} / \mathrm{ml}$ (Geneticin; Gibco Laboratories, Grand Island, NY). After $\sim 2$ wk, G418resistant clones were replated in fresh medium containing $0.25 \mu \mathrm{M}$ MTX (Lederle Laboratories, Pearl River, NY) plus dialyzed FCS. Surviving MTX-resistant clones were isolated using sterile glass cloning cylinders and expanded for continuous growth in $0.25 \mu \mathrm{M}$ MTX.

Southern analysis. $10 \mu \mathrm{g}$ of DNA from each clone and the vector transfected control line was cut to completion using XhoI under conditions recommended by the manufacturer (New England Biolabs Inc., Beverly, MA). Digested DNA was electrophoresed in a $1 \%$ Tris-acetate gel and transferred to a nylon filter (Hybond N; Amersham Corp. Arlington Heights, IL). The filter was hybridized with a random-primed, ${ }^{32} \mathrm{P}$-labeled cDNA insert probe from pIGF-IR.8 at $42^{\circ} \mathrm{C}$ overnight. The filter was washed twice at room temperature in $2 \times \mathrm{SSC}(1 \times \mathrm{SSC}=$ $0.15 \mathrm{M} \mathrm{NaCl}, 0.015 \mathrm{M}$ sodium citrate, $\mathrm{pH} \mathrm{7.0),0.1 \%} \mathrm{SDS} \mathrm{and} \mathrm{twice}$ at $55^{\circ} \mathrm{C}$ in $0.2 \times \mathrm{SSC}, 0.1 \%$ SDS before exposure to Kodak XAR film at $-80^{\circ} \mathrm{C}$ with an intensifying screen.

S1 nuclease protection assay. S1 nuclease mapping was performed by the method of Berk and Sharp (24) as modified by Weaver and
Weissmann (25) using an end-labeled DNA probe. The S1 probe was constructed by subcloning pIGF-IR.8 into the EcoRI site of Bluescript $\mathrm{SK}+$. This plasmid was constructed because no suitable restriction sites were present in $\mathrm{pSV}_{2}$ (dhfr) for the preparation of end-labeled probes. The resultant plasmid was linearized with NcoI, dephosphorylated, and end-labeled with T4 polynucleotide kinase $\left[\gamma^{32} \mathrm{P}\right]$ ATP. Cellular RNAs $(60 \mu \mathrm{g})$ were hybridized with the end-labeled DNA fragments $(50,000$ $\mathrm{dpm}$ ) for $16 \mathrm{~h}$ at $52^{\circ} \mathrm{C}$. The samples were digested with $\mathrm{S} 1$ nuclease and analyzed by autoradiography after electrophoresis on $8 \%$ polyacrylamide gels.

Immunofluorescence and flow cytometry. Cells were harvested from confluent dishes in PBS with $1 \mathrm{mM}$ EDTA, washed twice in ice-cold PBS, and then incubated for $30 \mathrm{~min}$ with antibody $\alpha \mathrm{IR}-3(0.25 \mu \mathrm{g} / \mathrm{ml})$ or a titered excess of an isotype-matched control mouse myeloma protein. After washing with cold staining medium (DME supplemented with $10 \%$ FCS and $2 \mathrm{mM}$ sodium azide), cells were incubated for $30 \mathrm{~min}$ with fluoresceinated affinity-purified goat antiserum to mouse immunoglobulin (Coulter Corp., Hialeah, FL). After further washing in cold staining medium, the cells were resuspended in staining medium containing $0.25 \mathrm{mM}$ propidium iodide and analyzed with an EPICS 753 flow cytometer (Coulter Corp.). The fluorescence scale was a 256channel/3-decade log scale. The relative fluorescence intensity (RFI) was determined by using the ratio of the mean channel of cells stained with $\alpha$ IR-3 compared with the same cells treated with the isotypematched myeloma control protein and were expressed relative to the control line (26).

IGF-I binding assay. For the IGF-I binding assay, confluent 6-well plates of cells were rinsed with $2 \mathrm{ml}$ of $120 \mathrm{mM} \mathrm{NaCl}, 1.2 \mathrm{mM} \mathrm{MgSO}_{4}$, $15 \mathrm{mM}$ NaOAc, $2.5 \mathrm{mM} \mathrm{KCl}, 10 \mathrm{mM}$ glucose, $1 \mathrm{mM}$ EDTA, $1 \%$ bovine

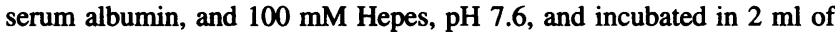
the same buffer containing radioiodinated IGF-I $(25 \mathrm{pM}, 2 \mu \mathrm{Ci} / \mathrm{pM}$; Amersham Corp.) along with varying concentrations of unlabeled ligand (0-100 nM; UBI, Lake Placid, NY) for $18 \mathrm{~h}$ at $4^{\circ} \mathrm{C}$. The incubation medium was aspirated, the monolayers were washed with $10 \mathrm{mM}$ Tris/ $\mathrm{HCl}(\mathrm{pH} \mathrm{7.4)}$ and $154 \mathrm{mM} \mathrm{NaCl}$, and the cells from each well were then lysed in $0.1 \%$ SDS for determination of cell-associated radioactivity. Binding was corrected for nonspecific ${ }^{125} \mathrm{I}-\mathrm{IGF}-\mathrm{I}$ binding to control cells ( $<5 \%$ of total) as determined in the presence of $100 \mathrm{nM}$ unlabeled IGF-I and was subtracted from each datum point. IGF-I binding was not specifically corrected for binding through the IGF-II receptor (4). Binding determinations were performed in triplicate for each concentration of unlabeled ligand and were normalized to total protein for each well. Binding data were analyzed by ENZFITTER (27).

In vitro and in vivo growth characteristics. In vitro growth rates were determined by plating cells at $7.5 \times 10^{4}$ cells per $35-\mathrm{mm}$ culture dish. Triplicate dishes of each clone were harvested and counted 1-5 d after plating in various concentrations of FCS. In vivo growth was assessed by injecting thymectomized, irradiated ( $925 \mathrm{cGy}$ ), marrowreconstituted CBA/CaJ female mice with $1.0 \times 10^{7}$ cells subcutaneously over each flank. Animals were examined every week for signs of tumor growth, and the dimensions were determined as described previously (28). Mice bearing tumors were killed when the tumor burden was $\sim 1$ $\mathrm{cm}^{3}$ or after $6 \mathrm{mo}$ in the absence of tumor growth.

\section{Results}

After cotransfection of the $\mathrm{Rh} 30$ alveolar rhabdomyosarcoma cell line with the IGF-IR antisense and $\mathrm{pSV}_{2}$ neo DNA, 18 G418resistant clones were obtained. To ascertain the uniqueness of these clones, we examined the integration site of the transfected plasmid by Southern analysis of genomic DNA cut with XhoI, which has only a single site in the transfected constructs. Thus, the size of the hybridizing fragment is dependent on the distance between the site of random integration of the transfected DNA and the nearest Xhol recognition sequence in the flanking genomic DNA. A Southern blot containing XhoI-digested DNA was 


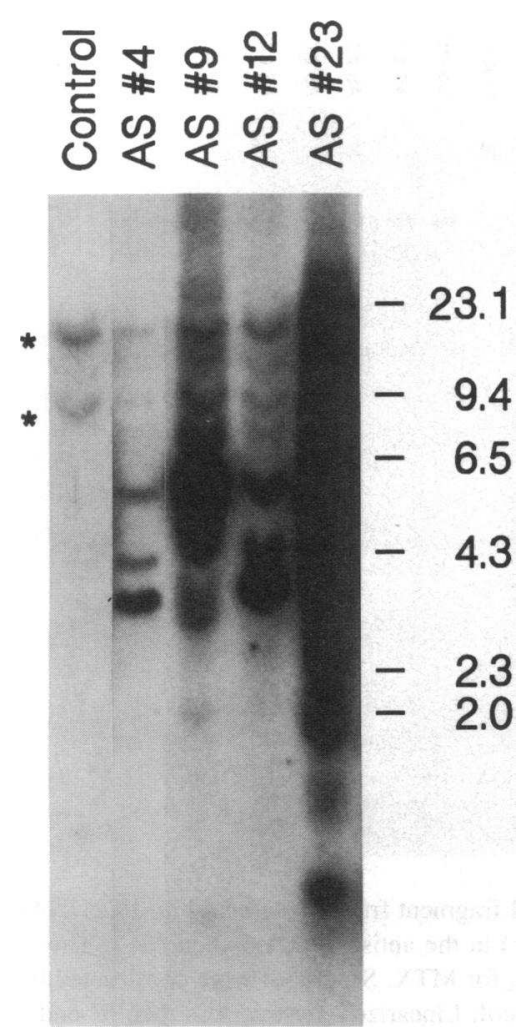

Figure 1. Southern analysis of XhoI-restricted DNA from control cells cotransfected with $\mathrm{pSV}_{2}$ (dhfr) and $\mathrm{pSV}_{2}$ neo as well as four independent IGF-IR antisense clones. The blot was probed with the 700-bp EcoRI fragment from the cDNA-containing plasmid pIGF-IR.8 and confirmed the presence of amplified and uniquely integrated plasmid inserts as well as the presence of fragments present from the endogenous IGF-IR gene (indicated by asterisks).

probed with a ${ }^{32} \mathrm{P}$-labeled fragment of the IGF-IR cDNA. This fragment contains a portion of the CDNA which is $3^{\prime}$ to the Xhol recognition site found in the transfected sequence and identifies IGF-IR germline fragments of 18 and $9.4 \mathrm{~kb}$ (Fig. 1). Four individual clones that uniquely integrated the IGF-IR antisense expression plasmid were chosen for further analysis after continuous growth in $0.25 \mu \mathrm{M}$ MTX. As shown in Fig. 1, all of the clones had multiple sites of integration of the plasmid in their genomic DNA; clone AS\#4 has a unique 3.5-kb band, clone AS\#9 has a 7-kb band, AS\#12 has a 4-kb band, and AS\#23 has a 2-kb band. Although the level of amplification of the antisense plasmid varies significantly between these clones, additional selection in higher concentrations of MTX failed to result in further amplification of IGF-IR sequences in any of these clones (data not shown). This result presumably was related to the fact that the high-level expression seen in these clones after their initial selection in $0.25 \mu \mathrm{M}$ MTX was sufficient to confer resistance to the higher concentration of the drug without concurrent dihydrofolate reductase amplification.

We next examined each unique clone for the expression of antisense IGF-IR transcripts by $\mathrm{S} 1$ nuclease protection assay. As shown in Fig. 2, the NcoI-linearized pIGF-IR construct results in the production of two 5'-end labeled S1 probes; one protecting the 586-nt endogenous transcript and the other protecting the 114-nt antisense transcript. The 114-nt antisense transcript was identified in all four clones but was absent in the vector-transfected control line. Barely detectable levels of antisense transcript were detectable in clone AS\#4, which also had the lowest level of amplification of the expression plasmid as determined by Southern blot. Clones AS\#9, AS\#12, and AS\#23 all had significantly higher levels of antisense transcripts, with AS\#23 expressing a two- to threefold greater level of antisense message compared with the other two.

Immunofluorescence with the IGF-IR monoclonal antibody ( $\alpha$ IR-3) was then performed to determine IGF-IR expression in the transfected clones, and the distribution of fluorescence intensity was assessed by flow cytometry (Fig. 3 ). The vectortransfected Rh30 control line expressed significant amounts of IGF-IR with an RFI of 4.2. Of the IGF-IR antisense transfectants, clone AS\#4, which had the lowest level of amplification of the antisense expression plasmid and the least amount of antisense transcript, expressed the highest level of IGF-IR with an RFI of 3.7. By contrast, the three other IGF-IR transfectants each expressed significantly less IGF-IR with RFI values of 2.8 , 2.4, and 2.3 for clones AS\#9, AS\#12, and AS\#23, respectively.

To determine more precisely the differences in IGF-IR protein expression between the transfectants, IGF-I binding assays were performed. The amount of IGF-I bound at various ligand concentrations was converted to a Scatchard plot and is displayed in the inset with each fluorescence histogram (Fig. 3). For each cell population, binding displayed saturation kinetics with half-maximal IGF-I binding occurring at $\sim 0.17 \mathrm{nM}$ with binding in all clones best fit by a one-site model. The number of receptors displayed by the vector-transfected control cells was $\sim 32,000 \pm 1,200$ (mean \pm SE), 27,000 $\pm 1,000$ for AS\#4, $19,000 \pm 1,100$ for AS\#9, $16,000 \pm 1,300$ for AS\#12, and $14,000 \pm 1,100$ for AS\#23. These results for IGF-IR number, as determined by binding assay, agree with the results obtained by flow cytometry. By contrast, IGF-IR affinity was not significantly different between the control cell line $(0.49 \pm 0.07 \mathrm{nM}$, mean $\pm \mathrm{SE}$ ) and any of the transfected cell lines (mean for all antisense transfectants $0.56 \pm 0.12 \mathrm{nM}$ ). These data indicate that the decreased binding in the antisense vector-transfected cells was accounted for by diminished receptor numbers at the cell surface without changes in receptor affinity.

The effects of IGF-IR antisense expression on the in vitro growth characteristics of the transfected clones were next examined. The growth rates of the antisense clones were compared with that of the vector-transfected control and are shown in Fig. 4. A marked reduction in growth rates for antisense clones AS\#9, AS\#12, and AS\#23 was observed at all serum concentrations tested compared with control cells and AS\#4; these differences were most pronounced for growth in $2 \%$ serum. Cell viability remained the same for all groups throughout the course of these experiments $(>95 \%)$, indicating that our results did not simply reflect reduced viability of antisense clones. These results could be explained in part by the titration of other nonautocrine growth factors normally present in serum and necessary for optimal growth of mesenchymally derived cells (29).

The effect of reduced IGF-IR expression on anchorage-independent growth was also investigated (Table I). The cells were plated in soft agar with heat-inactivated, dialyzed $10 \%$ FCS, and plates were examined $21 \mathrm{~d}$ later. Single cells, small colonies of $\sim 50$ cells, and large colonies of several hundred cells were readily distinguishable. Both the parental Rh30 cell line and the vector-transfected control formed large numbers of colonies. All four transfectants demonstrated decreased cloning efficiency, although the plating efficiency of clone AS\#4 was most similar 

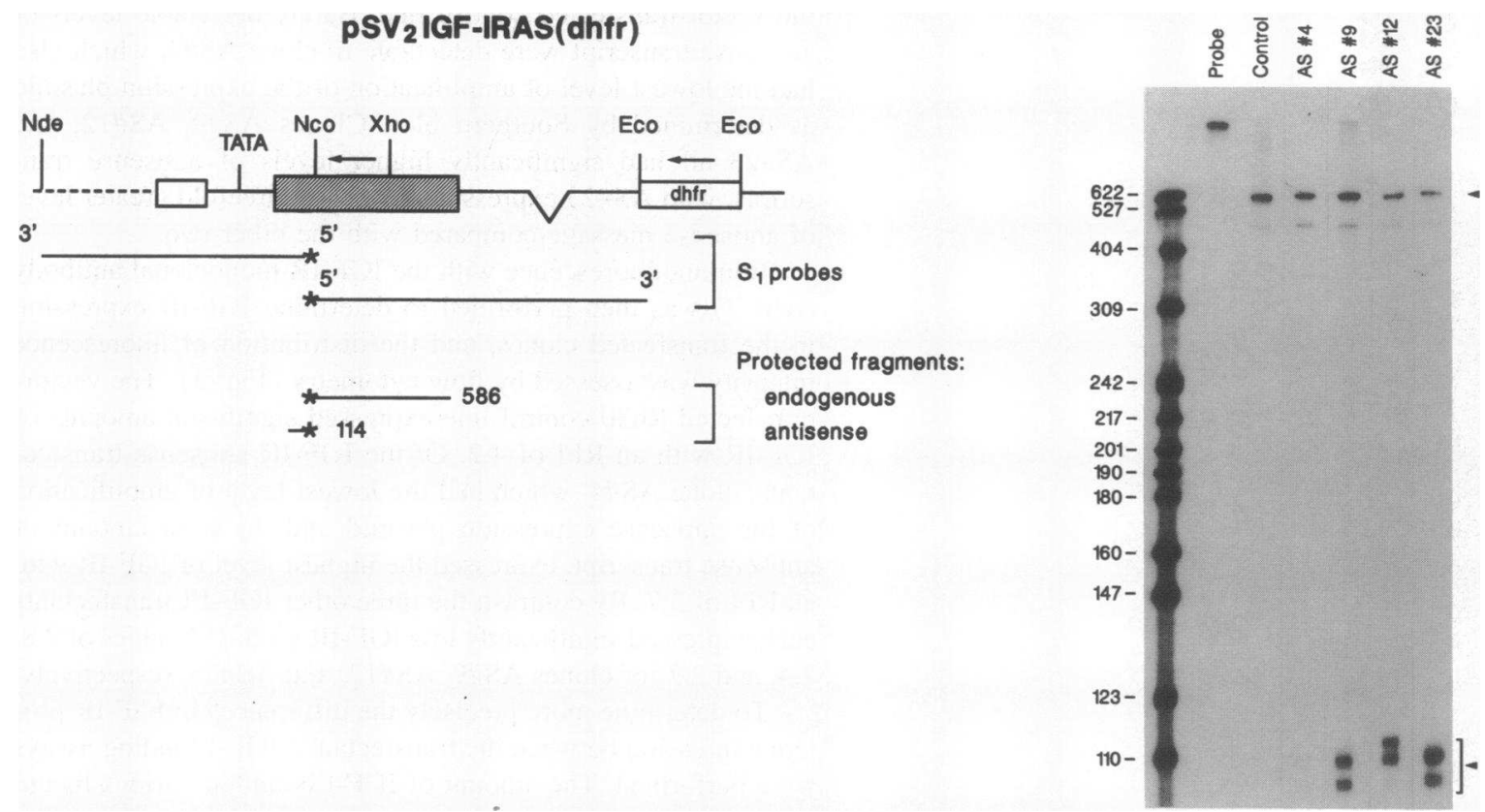

Figure 2. The $\mathrm{pSV}_{2}$ IGF-IRAS(dhfr) plasmid (left) was constructed by blunt-end cloning a 700-bp EcoRI fragment from the human IGF-IR cDNAcontaining plasmid pIGF-IR.8 into a unique SmaI site of the mammalian expression plasmid $\mathrm{pSV}_{2}(\mathrm{dhfr})$ in the antisense orientation (21). This plasmid contains a complete transcription unit for a mutant dihydrofolate reductase with an increased $K_{\mathrm{m}}$ for MTX. S1 probes were constructed by subcloning pIGF-IR.8 into the EcoRI site of Bluescript SK and linearizing the resultant plasmid with NcoI. Linearized plasmid was then 5'-end labeled for S1 analysis of RNA from selected antisense clones. These probes protect a fragment of $586 \mathrm{nt}$ from the endogenous IGF-IR transcript and a fragment of $114 \mathrm{nt}$ from the antisense transcript (arrows). S1 analysis (right) of RNA from control cells cotransfected with the parental vector $\mathrm{pSV}_{2}$ (dhfr) plus $\mathrm{pSV}_{2}$ neo, as well as four independent IGF-IR antisense clones. All clones contain approximately equivalent amounts of the endogenous 586-nt transcript. Whereas AS\#9, AS\#12, and AS\#23 contain large amounts of the 114-nt antisense transcript, the MTX-resistant antisense clone AS\#4 contains barely detectable levels of antisense message. The double bands present in the protected antisense transcripts are presumably due to transcriptional stuttering at the initiation site.

to the controls and greater than each of the other three transfectants. Decreased cloning efficiency was correlated with reduced IGF-IR expression by growing the cells in the presence of $\alpha \mathrm{IR}$ 3 , a monoclonal antibody specific for IGF-IR. In all cases, antibody treatment resulted in a significant further reduction in plating efficiency. This antibody has been shown to attach at the ligand-binding site, prevent IGF-I and IGF-II binding, and block IGF-I-mediated receptor activation $(6,30-32)$. Although the antibody can directly stimulate the receptor, it did not do so at the concentration that was chosen (33). These results demonstrate that expression of the IGF-IR may be responsible in part for the anchorage-independent growth of $\mathrm{Rh} 30$ cells and that a reduction in receptor number results in decreased cloning efficiency.

Finally, it was of interest to examine the in vivo effect of reduced IGF-IR expression on tumor formation in immunodeficient mice (Table II). The AS\#4 cells formed tumors rapidly, and within 1 wk mice injected with $10^{7}$ cells all developed visible, firm, subcutaneous nodules at the injection site. These grew progressively and reached a tumor volume of $1 \mathrm{~cm}^{3}$ in a median time of $37 \mathrm{~d}$. This pattern of growth was very similar to animals that were injected with vector-transfected cells. Pathologic examinations of the tumors in animals injected with AS\#4 cells were similar to those of control animals, consisting of nested tumor cells interrupted by occasional fibrous septa. By contrast, animals injected with an equivalent number of cells from clone AS\#9 formed only a single tumor and those injected with clone AS\#23 failed to develop tumors after being moni- tored for over 6 mo. These results suggest that reduction in IGF-IR expression can abrogate tumor growth in vivo.

\section{Discussion}

Previous studies with NIH 3T3 cells have established a relationship between IGF-IR overexpression and ligand-dependent neoplastic transformation (15) as well as demonstrating that constitutive high-level expression of both this receptor and IGF-I abrogates all requirements for any other exogenous growth factors (34). To establish a direct relationship between IGF-IR expression and tumorigenicity in a human tumor model system, we used antisense-mediated inhibition of IGF-IR expression in alveolar rhabdomyosarcoma, a tumor derived from fetal skeletal muscle. This approach is a powerful tool for modulating the synthesis of specific proteins. It has been used in the past to investigate the role of oncogenes such as c-fos and c-myc in the control of cell proliferation and differentiation $(17,21)$ as well as to modulate the production of the extracellular matrix components, tissue inhibitor of metalloproteinase and thrombospondin, in order to study their roles in tumor metastasis (35, 36). Our present work extends this approach by reducing cellsurface expression of IGF-IR with resultant inhibition of both the in vitro and in vivo growth of the tumor.

Four unique antisense-transfected clones were obtained with reduced expression of IGF-IR. The degree to which clonal variation affects IGF-IR expression in individual cell lines was determined by assessing IGF-IR surface expression in three unique 


\section{Control}

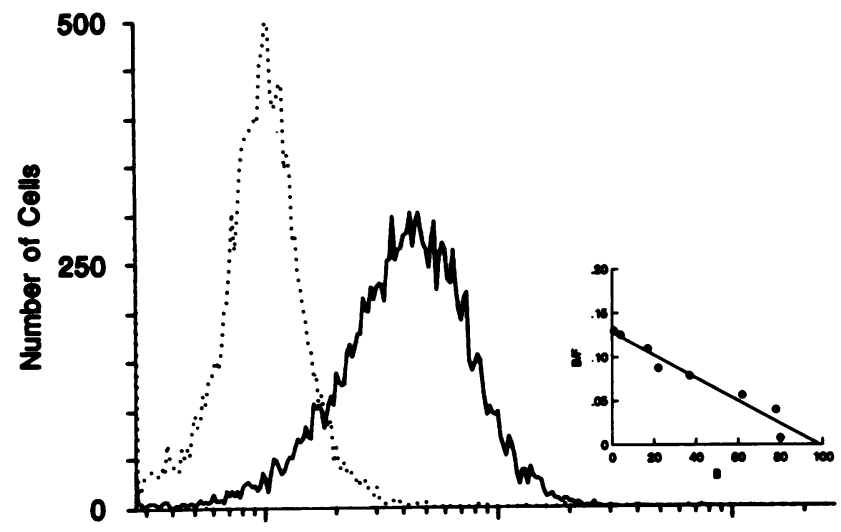

AS*9

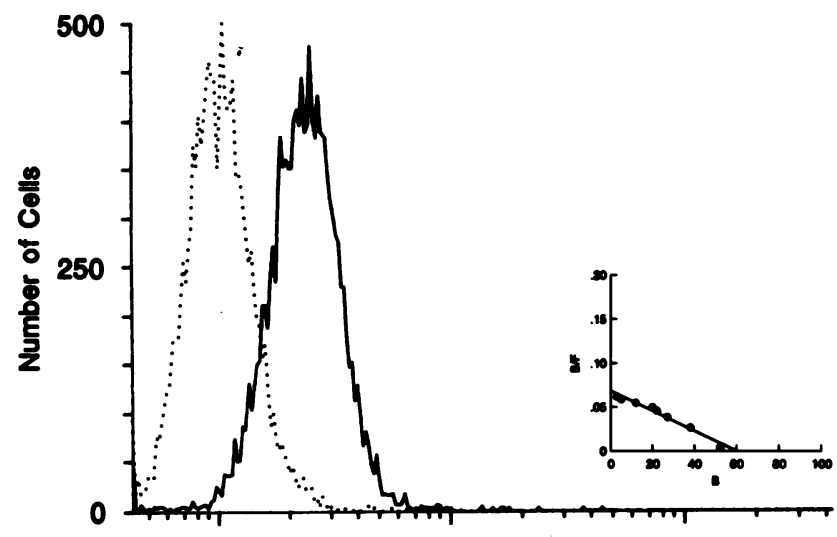

AS\#23
AS\#4
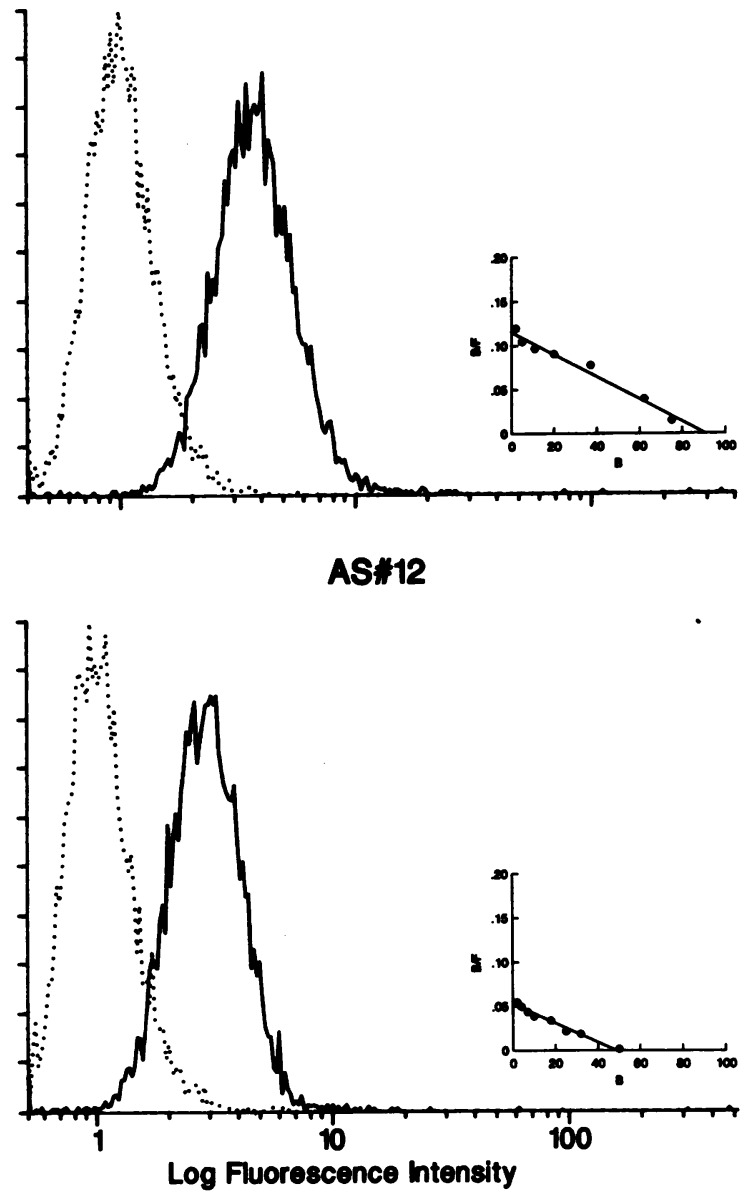

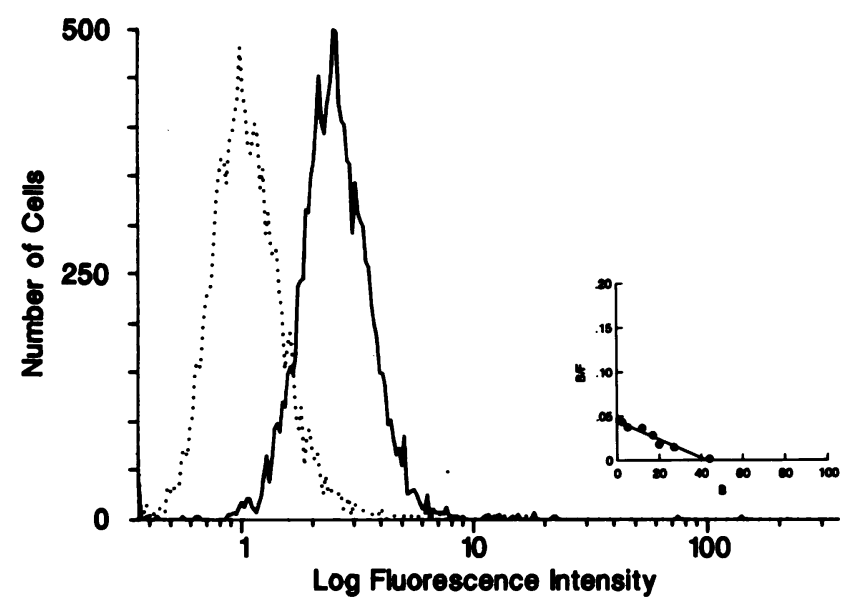

Figure 3. Flow cytometric analysis of control and antisense clones stained with the IGF-IR monoclonal antibody $\alpha$ IR 3 demonstrating reduced density of IGF-I receptors on transfected cells. The RFI was calculated from the mean channel number for each clone stained with $\alpha$ IR3 (continuous lines) compared with the same cells stained with an isotype-matched myeloma control antibody (dotted lines) and is shown expressed relative to the control line. Antisense transfectants all expressed reduced levels of IGF-I receptors on their cell surface relative to the control cell line. Insets represent Scatchard plots of IGF-I binding sites determined with increasing concentrations of IGF-I. A representative of three separate experiments is shown. Each point represents the mean of triplicate values. Antisense transfectants all had quantitatively reduced number of IGF-I receptors compared with the control cell line (see Results).

vector control lines. Clonal variation in IGF-IR expression was $<10 \%$ in these control lines and could not account for the significant reduction observed in each of the antisense clones (data not shown). It is clear that the phenotypic changes observed were mediated through reduced expression of IGF-IR since IGF-IR surface expression was reduced in relative propor- 

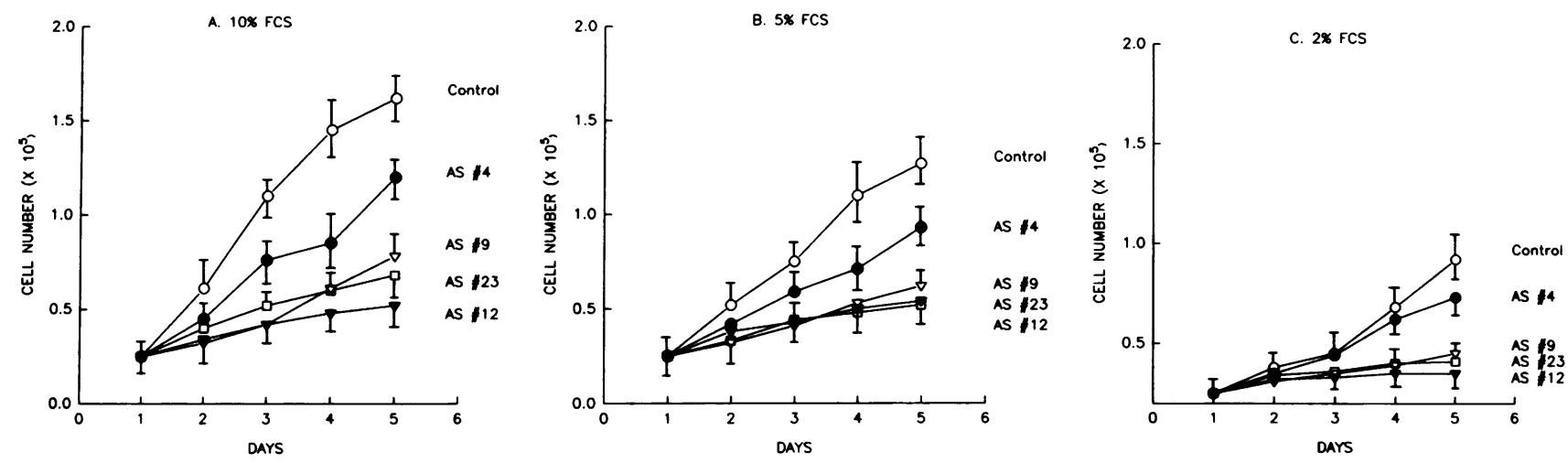

Figure 4. Growth rates of parental Rh30 line, control clone cotransfected with $\mathrm{pSV}_{2}(\mathrm{dhfr})$ and $\mathrm{pSV}_{2}$ neo, and four independent IGF-IR antisense clones grown in $10(A), 5(B)$, and $2(C)$ FCS. Logarithmically growing cells in medium containing $10 \%$ FCS were plated at $7.5 \times 10^{4}$ cells/ dish in 35-mm dishes. Triplicate cultures were harvested for counting 1-5 d after plating. A representative of four separate experiments is shown. Each point represents the mean of triplicate values. Standard errors are indicated. Antisense clones AS\#9, AS\#12, and AS\#23 grew slower than the vector-transfected control line or the parental line.

tion to $(a)$ the degree of amplification of integrated sequences as assessed by Southern hybridization; $(b)$ the amount of antisense RNA as detected by $\mathrm{S} 1$ nuclease protection assay; and $(c)$ receptor number as determined by immunofluorescence and Scatchard analysis. Furthermore, expression of similar antisense constructs for two other genes whose transcripts are expressed in $\mathrm{Rh} 30$ cells (MyoD1 and desmin) did not decrease IGF-I receptor density or alter anchorage-independent growth (data not shown).

The above results were mirrored by both the in vitro and in vivo growth characteristics of the IGF-IR antisense transfectants. A marked reduction in in vitro growth rates was observed for the three clones with the greatest diminution in IGF-IR density, whereas the single clone (AS\#4) with receptor numbers most similar to the vector control grew more rapidly. Similar results were also obtained when the anchorage-independent growth of the transfectants was determined in soft agar. Decreased cloning efficiency was correlated with reduced IGF-IR

Table I. Colony Formation in Soft Agar*

\begin{tabular}{lcc}
\hline \multicolumn{1}{c}{ Cell type } & Addition & Number of colonies $^{\ddagger}$ \\
\hline Rh30 (parental line) & - & 163 \\
Rh 30 (parental & & \\
line) & $\alpha \mathrm{IR3}$ & 3 \\
Vector control & - & 180 \\
Vector control & $\alpha \mathrm{IR3}$ & 4 \\
AS\#4 & - & 143 \\
AS\#4 & $\alpha \mathrm{IR3}$ & 1 \\
AS\#9 & - & 86 \\
AS\#9 & $\alpha \mathrm{IR3}$ & 3 \\
AS\#12 & - & 64 \\
AS\#12 & $\alpha \mathrm{IR3}$ & 6 \\
AS\#23 & - & 45 \\
AS\#23 & $\alpha \mathrm{IR3}$ & 5 \\
\hline
\end{tabular}

* 2,500 cells were plated in $0.3 \%$ agar with $10 \%$ FCS. When $\alpha$ IR3 was incorporated into the agar, the final concentration was $0.5 \mu \mathrm{g} / \mathrm{ml}$. Plates were scored at $21 \mathrm{~d}$, and only colonies with at least 50 cells were counted. ${ }^{\ddagger}$ Mean of triplicate plates, which agreed to within $10 \%$. expression; the specificity of this observation was confirmed by incubation with IGF-IR monoclonal antibody, resulting in a further attenuation in plating efficiency. This antibody specifically blocks human IGF-IR activation and has been reported previously to inhibit the growth of cultured Wilms' tumor cells, rhabdomyoblasts, and NIH 3T3 transfectants overexpressing the receptor $(6,15,37)$. These results implicate the IGF-IR, at least in part, for the anchorage-independent growth of $\mathrm{Rh} 30$ cells.

The IGF-IR antisense transfectants were tested for tumorigenicity in immune-deficient mice to determine whether decreased receptor density in vivo is sufficient to suppress the malignant phenotype of this tumor. In these mice, antisense clone AS\#9 had greatly reduced tumorigenicity, and AS\#23 failed to produce tumors through the 6-mo duration of the study. By contrast, both the vector control line and AS\#4, the antisense clone with the highest receptor density, formed tumors rapidly in all animals that were inoculated. These data suggest there is a critical threshold for IGF-IR density required for the neoplastic growth of $\mathrm{Rh} 30$ cells in vivo.

This study demonstrates the importance of the interaction of IGF-IR with its ligand(s) for the autocrine or paracrine growth of human rhabdomyosarcoma. The cognate ligand for IGF-IR, IGF-I, is a ubiquitous requirement for the growth of all cells in vitro, and under certain conditions this ligand-receptor system is the sole requirement for the growth of murine fibroblasts (34). In these studies as well as those of Kaleko (15),

Table II. Growth of IGF-IR Antisense Clones in Immunodeficient Mice

\begin{tabular}{lccl}
\hline Clone & Inoculations* & Tumors & Median days to reach $\mathbf{1 \mathbf { c m } ^ { 3 }}$ \\
\hline & $n$ & $n$ & \\
Vector & 14 & 14 & 34 \\
AS\#4 & 10 & 10 & 37 \\
AS\#9 & 12 & 1 & Day 37 \\
AS\#23 & 12 & $0^{\ddagger}$ & - \\
\end{tabular}

* $10^{7}$ cells were injected subcutaneously into two sites per mouse. $\quad{ }^{\ddagger} \mathrm{Ex}-$ periment terminated at 6 mo after inoculation. 
the magnitude of proliferation or ligand-dependent growth was related directly to IGF-IR density; IGF-I was found to be $\sim 50$ fold more potent than insulin in promoting anchorage-independent growth consistent with its higher affinity for IGF-IR (2, 15). Our studies did not directly address whether the IGF-I or IGF-II interaction with IGF-IR is responsible for the autocrine growth of rhabdomyosarcoma cells. However, recent evidence has implicated IGF-II-mediated signaling through IGF-IR as critical to the proliferation of both rhabdomyosarcomas and neuroblastomas $(6,38,39)$. In this regard, Rh30 cells have been shown to express high levels of IGF-II mRNA as well as to secrete IGF-II in culture (our unpublished results and reference 6).

Additionally, we also observed a relationship between the reduction in IGF-IR number and the phenotypic characteristics of Rh30 cells transfected with the antisense IGF-IR; clones with the greatest decrease in IGF-IR expression also displayed the most impaired growth. Thus, it would appear that IGF-IR density is a rate-limiting feature for the in vitro and in vivo growth and tumorigenicity of Rh30 rhabdomyoblasts. Recent evidence suggests that common both to IGF-IR and insulin receptor signal transduction is specific tyrosine phosphorylation of the major insulin receptor substrate (IRS-1) and coupling to downstream Ras signaling pathways (40-43). It seems reasonable to conclude, therefore, that an amplified signal proportional to receptor numbers may play a role in the growth regulation of rhabdomyosarcoma.

In conclusion, these results demonstrate that stable reduction of IGF-IR expression by antisense RNA can alter the malignant phenotype of a human rhabdomyosarcoma cell line as assessed by the analysis of both in vitro and in vivo growth characteristics. By altering the synthesis of this protein, we may have interfered with a critical autocrine loop necessary for the unrestrained growth of this tumor. Whereas this is speculation at present, this study provides insight into the importance of the IGF-IR and its ligand(s) in tumorigenesis.

\section{Acknowledgments}

We are grateful to Dr. Richard Ashmun for assistance with flow cytometry and for the technical support of Sandra Farmer, Sharon Nooner, and Glen Germain.

This work was supported in part by grant CA-23099 and Cancer Center CORE Grant CA-21765 from the National Institutes of Health and the American Lebanese Syrian Associated Charities.

\section{References}

1. Rechler, M. M., and S. P. Nissley. 1990. Insulin-like growth factors. In Peptide Growth Factors and Their Receptors. Volume 95 of Handbook of Experimental Pharmacology. M. B. Sporn and A. B. Roberts, editors. Springer-Verlag New York Inc., New York. 263-367.

2. LeRoith, D., M. Adamo, H. Werner, and C. T. Roberts, Jr. 1991. Insulinlike growth factors and their receptors as growth regulators in normal physiology and pathological states. Trends Endocrinol. Metab. 2:134-139.

3. Shimizu, M., C. Webster, D. O. Morgan, H. M. Blau, and R. A. Roth. 1986. Insulin and insulinlike growth factor receptors and responses in cultured human muscle cells. Am. J. Physiol. 251:E611-E615.

4. Morgan, D. O., J. C. Edman, D. N. Standring, V. A. Fried, M. C. Smith R. A. Roth, and W. J. Rutter. 1987. Insulin-like growth factor II receptor as a multifunctional binding protein. Nature (Lond.). 329:301-307.

5. Roth, R. A. 1988. Structure of the receptor for insulin-like growth factor II: the puzzle amplified. Science (Wash. DC). 239:1269-1271.

6. El-Badry, O. M., C. Minniti, E. C. Kohn, P. J. Houghton, W. H. Daughaday, and L. J. Helman. 1990. Insulin-like growth factor II acts as an autocrine growth and motility factor in human rhabdomyosarcoma tumors. Cell Growth \& Differ. 1:325-331.

7. Minniti, C. P., E. C. Kohn, J. H. Grubb, W. S. Sly, Y. Oh, H. L. Muller, R. G. Rosenfeld, and L. J. Helman. 1992. The insulin-like growth factor II (IGFII)/mannose 6-phosphate receptor mediates IGF-II-induced motility in human rhabdomyosarcoma cells. J. Biol. Chem. 267:9000-9004.

8. Tollefsen, S. E., R. Lajara, R. H. McCusker, D. R. Clemmons, and P. Rotwein. 1989. Insulin-like growth factors (IGF) in muscle development. Expression of IGF-I, the IGF-I receptor, and an IGF binding protein during myoblast differentiation. J. Biol. Chem. 264:13810-13817.

9. Tollefsen, S. E., J. L. Sadow, and P. Rotwein. 1989. Coordinate expression of insulin-like growth factor II and its receptor during muscle differentiation. Proc. Natl. Acad. Sci. USA. 86:1543-1547.

10. Florini, J. R., K. A. Magri, D. Z. Ewton, P. L. James, K. Grindstaff, and P. S. Rotwein. 1991. "Spontaneous" differentiation of skeletal myoblasts is dependent upon autocrine secretion of insulin-like growth factor-II. J. Biol. Chem. 266:15917-15923.

11. Rosenthal, S. M., A. Brunetti, E. J. Brown, P. W. Mamula, and I. D. Goldfine. 1991. Regulation of insulin-like growth factor (IGF) I receptor expression during muscle cell differentiation. Potential autocrine role of IGF-II. J. Clin. Invest. 87:1212-1219.

12. Macaulay, V. M. 1992. Insulin-like growth factors and cancer. Br. $J$. Cancer. 65:311-320.

13. Roholl, P. J., A. Skottner, I. Prinsen, C. J. Lips, W. Den Otter, and J. A. Van Unnik. 1990. Expression of insulin-like growth factor 1 in sarcomas. Histopathology (Oxf.). 16:455-460.

14. Garvin, A. J., T. Gansler, W. Gerald, and D. A. Sens. 1991. Insulin-like growth factor production by childhood solid tumors. Perspect. Pediatr. Pathol. 15:106-116.

15. Kaleko, M., W. J. Rutter, and A. D. Miller. 1990. Overexpression of the human insulinlike growth factor I receptor promotes ligand-dependent neoplastic transformation. Mol. Cell. Biol. 10:464-473.

16. Kim, S. K., and B. J. Wold. 1985. Stable reduction of thymidine kinase activity in cells expressing high levels of anti-sense RNA. Cell. 42:129-138.

17. Holt, J. T., T. V. Gopal, A. D. Moulton, and A. W. Nienhuis. 1986. Inducible production of c-fos antisense RNA inhibits 3T3 cell proliferation. Proc. Natl. Acad. Sci. USA. 83:4794-4798.

18. Douglass, E. C., M. Valentine, E. Etcubanas, D. Parham, B. L. Webber, P. J. Houghton, J. A. Houghton, and A. A. Green. 1987. A specific chromosomal abnormality in rhabdomyosarcoma. Cytogenet. Cell Genet. 45:148-155.

19. Kull, F. C., S. Jacobs, Y. F. Su, M. E. Svobuda, J. J. Van Wyk, and P. Cuatrecasas. 1983. J. Biol. Chem. 258:6561-6566.

20. Ullrich, A., A. Gray, A. W. Tam, T. Yang-Feng, M. Tsubokawa, C Collins, W. Henzel, T. Le Bon, S. Kathuria, E. Chen, et al. 1986. Insulin-like growth factor I receptor primary structure: comparison with insulin receptor suggests structural determinants that define functional specificity. EMBO (Eur. Mol. Biol. Organ.) J. 5:2503-2512.

21. Prochownik, E. V., and J. Kukowska. 1986. Deregulated expression of cmyc by murine erythroleukaemia cells prevents differentiation. Nature (Lond.). 322:848-850.

22. Southern, P. J., and P. Berg. 1982. Transformation of mammalian cells to antibiotic resistance with a bacterial gene under control of the SV40 early region promoter. J. Mol. Appl. Genet. 1:327-341.

23. Chen, C., and H. Okayama. 1988. Calcium phosphate-mediated gene transfer: a highly effective system for stably transforming cells with plasmid DNA. Biotechniques. 6:632-688.

24. Berk, A. J., and P. A. Sharp. 1977. Sizing and mapping of early adenovirus mRNAs by gel electrophoresis of $\mathrm{S} 1$ endonuclease-digested hybrids. Cell. 12:721-732.

25. Weaver, R. F., and C. Weissmann. 1979. Mapping of RNA by a modification of the Berk-Sharp procedure: the $5^{\prime}$ termini of $15 \mathrm{~S} \beta$-globin mRNA precursor and mature $10 \mathrm{~S} \beta$-globin mRNA have identical map coordinates. Nucleic Acids Res. 7:1175-1193.

26. Jennings, L. K., R. A. Ashmun, W. C. Wang, and M. E. Dockter. 1986. Analysis of human platelet glycoprotein IIb-IIIa and Glanzmann's thrombasthenia in whole blood by flow cytometry. Blood. 68:173-179.

27. Leatherbarrow, R. J. 1987. ENZFITTER. Elsevier-Biosoft, Cambridge. $13-62$.

28. Houghton, J. A., and D. M. Taylor. 1978. Growth characteristics of human colorectal tumours during serial passage in immune-deprived mice. Br. J. Cancer. 37:213-221.

29. Florini, J. R., D. Z. Ewton, and K. A. Magri. 1991. Hormones, growth factors, and myogenic differentiation. Annu. Rev. Physiol. 53:201-216.

30. Conover, C. A., R. L. Misra, R. L. Hintz, and R. G. Rosenfeld. 1986. Effect of an anti-insulin-like growth factor I receptor antibody of insulin-like growth factor II stimulation of DNA synthesis in human fibroblasts. Biochem. Biophys. Res. Commun. 139:501-508.

31. Flier, J. S., P. Usher, and A. C. Moses. 1986. Monoclonal antibody to the type I insulin-like growth (IGF-I) receptor blocks IGF-I receptor mediated DNA 
synthesis: clarification of the mitogenic mechanisms of IGF-I and insulin in human skin fibroblasts. Proc. Natl. Acad. Sci. USA. 83:664-668.

32. Rohlik, Q. T., D. Adams, F. C. Kull, Jr., and S. Jacobs. 1987. An antibody to the receptor for insulin-like growth factor I inhibits the growth of MCF-7 cells in tissue culture. Biochem. Biophys. Res. Commun. 149:276-281.

33. Xiong, L., J. Kasuya, S. L. Li, J. Kato, and Y. Fujita-Yamaguchi. 1992. Growth-stimulatory monoclonal antibodies against human insulin-like growth factor I receptor. Proc. Natl. Acad. Sci. USA. 89:5356-5360.

34. Pietrzkowski, Z., R. Lammers, G. Carpenter, A. M. Soderquist, M. Limardo, P. D. Phillips, A. Ullrich, and R. Baserga. 1992. Constitutive expression of insulin-like growth factor 1 and insulin-like growth factor 1 receptor abrogates all requirements for exogenous growth factors. Cell Growth \& Differ. 3:199-205.

35. Khokha, R., P. Waterhouse, S. Yagel, P. K. Lala, C. M. Overall, G. Norton, and D. T. Denhardt. 1989. Antisense-RNA induced reduction in murine TIMP levels confers oncogenecity on Swiss 3T3 cells. Science (Wash. DC). 243:947-949.

36. Castle, V., J. Varani, S. Fligiel, E. V. Prochownik, and V. Dixit. 1991. Antisense-mediated reduction in thrombospondin reverses the malignant phenotype of a human squamous carcinoma. J. Clin. Invest. 87:1883-1888.

37. Gansler, T., R. Furlanetto, T. S. Gramling, K. A. Robinson, N. Blocker, M. G. Buse, D. A. Sens, and A. J. Garvin. 1989. Antibody to type I insulinlike growth factor receptor inhibits growth of Wilms' tumor in culture and in athymic mice. Am. J. Pathol. 135:961-966.
38. El-Badry, O. M., J. A. Romanus, L. J. Helman, M. J. Cooper, M. M. Rechler, and M. A. Israel. 1989. Autonomous growth of a human neuroblastoma cell line is mediated by insulin-like growth factor II. J. Clin. Invest. 84:829-839.

39. El-Badry, O. M., L. J. Helman, J. Chatten, S. M. Steinberg, A. E. Evans, and M. A. Israel. 1991. Insulin-like growth factor II-mediated proliferation of human neuroblastoma. J. Clin. Invest. 87:648-657.

40. Giorgetti, S., R. Ballotti, A. Kowalski-Chauvel, S. Tartare, and E. Van Obberghen. 1993. The insulin and insulin-like growth factor-I receptor substrate IRS-1 associates with and activates phosphatidylinositol 3-kinase in vitro. J. Biol. Chem. 268:7358-7364.

41. Meyers, M. G., Jr., X. J. Sun, B. Cheatham, B. R. Jachna, E. M. Glasheen, J. M. Backer, and M. F. White. 1993. IRS-1 is a common element in insulin and insulin-like growth factor-I signaling to the phosphatidylyinositol 3'-kinase. Endocrinology. 132:1421-1430.

42. Baltensperger, K., L. M. Kozma, A. D. Cherniack, J. K. Klarlund, A. Chawla, U. Banerjee, and M. P. Czech. 1993. Binding of the ras activator son of sevenless to insulin receptor substrate-1 signaling complexes. Science (Wash. DC). 260:1950-1952.

43. Skolnik, E. Y., A. Batzer, N. Li, C.-H. Lee, E. Lowenstein, M. Mohammadi, B. Margolis, and J. Schlessinger. 1993. The function of GRB2 in linking the insulin receptor to ras signaling pathways. Science (Wash. DC). 260:19531955 